\title{
The impact of plantar fasciitis on glucose and AIC (GH-method: math-physical medicine)
}

\section{Introduction}

The author is investigating the impact of plantar fasciitis on postprandial plasma glucose (PPG) and $\mathrm{HbA1C}$ based on 522 data collected for a period of 174 days from 10/28/2018 to 4/27/2019 with post-meal walking steps, carbs/sugar intake grams, and measured PPG. The dataset is provided by the author, who uses his own type 2 diabetes (T2D) metabolic conditions control, as a case study via the "math-physical medicine" approach of a non-traditional methodology in medical research.

Math-physical medicine (MPM) starts with the observation of the human body's physical phenomena (not biological or chemical characteristics), collecting elements of the disease related data (preferring big data), utilizing applicable engineering modeling techniques, developing appropriate mathematical equations (not just statistical analysis), and finally predicting the direction of the development and control mechanism of the disease.

\section{Method}

In 2018 , this patient walked 18,458 steps daily $(\sim 7.7$ miles or $\sim 12.3 \mathrm{~km}$ ), where each heel took 9,229 impact force per day. During the second half of 2018 while he was traveling, he wore a pair of leisure shoes instead of his customized shoes with protective insoles. Towards the end of 2018, his plantar fasciitis condition returned. As a result, he could not walk as much as usual due to the sharp pain in his heels. By March of 2019, he noticed his increased values of PPG and

\author{
Volume 5 Issue 3 - 2020
}

\section{Gerald C Hsu}

Medical Research Scientist, eclaireMD Foundation, USA

Correspondence: Gerald C Hsu, Medical Research Scientist, eclaireMD Foundation, USA, Email g.hsu@eclairemd.com

Received: May 02, 2020 | Published: May 18, 2020

HbA1C. The author then utilized his MPM approach and his previous published papers to analyze his personalized data.

\section{Results}

During the plantar fasciitis period, his post-meal waking steps reduced by 1,800 steps from 4,800 to 3,000 . Based on the author's exercise formula (Figures 1) (Figure 2), every block of one thousand steps decreased approximately $5 \mathrm{mg} / \mathrm{dL}$ of PPG. The 1,800 steps reduction would increase PPG value by $9 \mathrm{mg} / \mathrm{dL}$. This estimation is quite comparable with the actual increase amount of PPG of $10 \mathrm{mg} /$ $\mathrm{dL}$ from 112 to 122 . The minor difference of $1 \mathrm{mg} / \mathrm{dL}$ is resulted from a variance of carbs/sugar intake amount. ${ }^{1-5}$

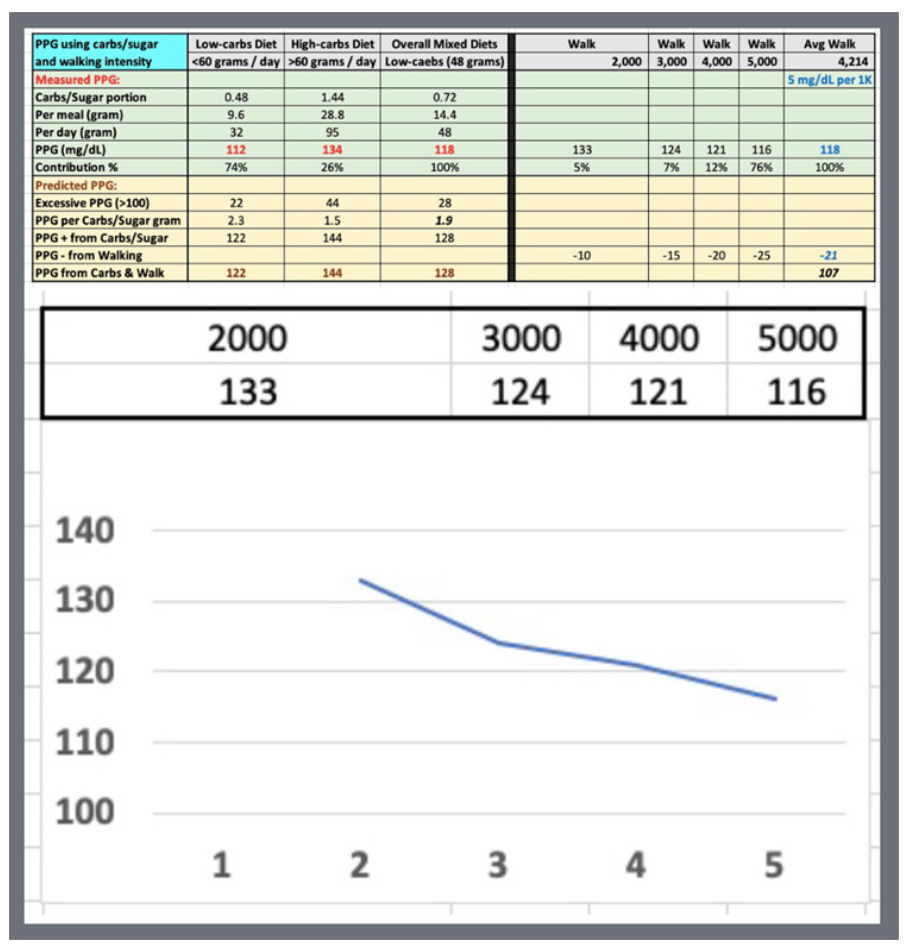

Figure I Formulas for PPG vs. diet/exercise. 


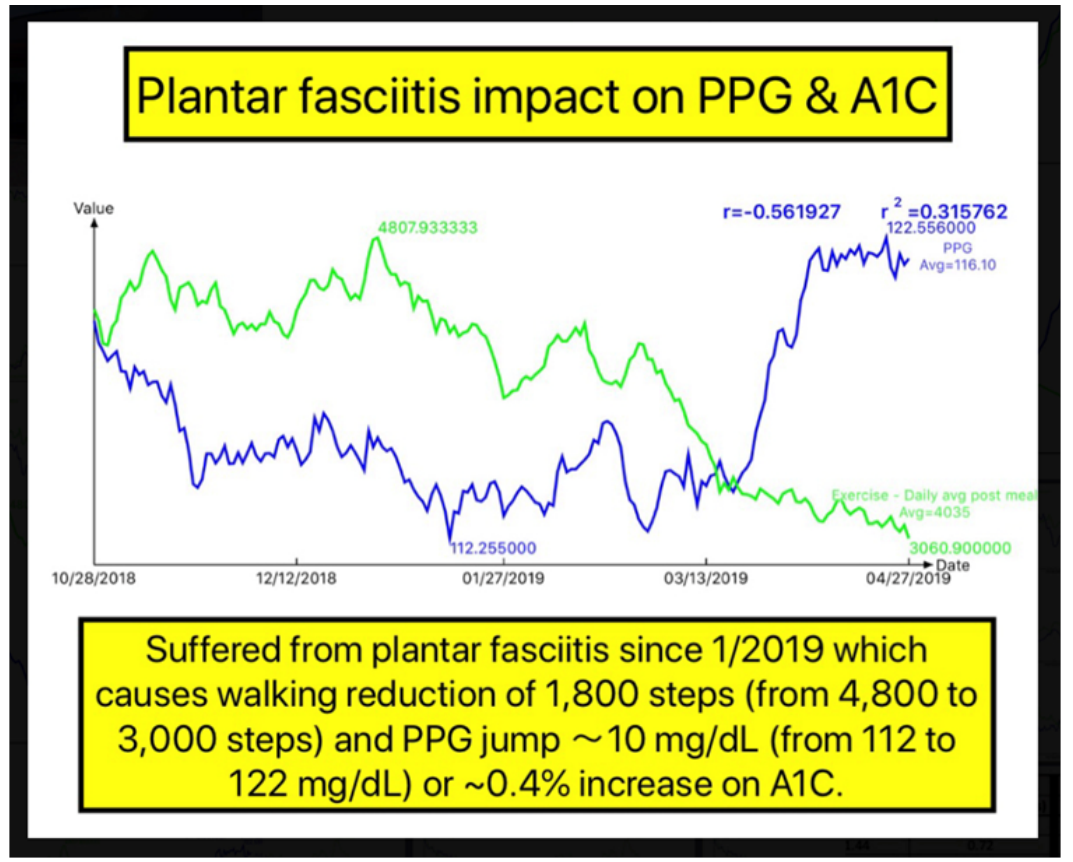

Figure 2 Plantar fasciitis impact on PPG and AIC.

\section{Conclusion}

This special clinical case demonstrates the inter-connectivity among different parts of the human body. Even having plantar fasciitis could increase a patient's glucose and A1C significantly. It also shows the importance of lifestyle management, including both diet and exercise, to diabetes patients. Finally, the MPM approach can be used to analyze many biomedical phenomena as long as the "related and clean" data are collected and organized efficiently.

\section{Acknowledgments}

First and foremost, the author wishes to express his sincere appreciation to a very important person in his life, Professor Norman Jones at MIT and University of Liverpool. Not only did he give him the opportunity to study for his $\mathrm{PhD}$ at MIT, but he also trained him extensively on how to solve difficult problems and conduct any basic scientific research with a big vision, pure heart, and integrity.

The author would also like to thank Professor James Andrews at the University of Iowa. He helped and supported him tremendously when he first came to the United States. He believed in him and prepared him to build his solid engineering and computer science foundation. $\mathrm{He}$ is forever grateful to his mentor, who has a kind heart and guided him during his undergraduate and master's degree work at Iowa.

\section{Conflicts of interest}

The authors declare have no conflict of interest about the publication of this paper.

\section{References}

1. Hsu GC. Using math-physical medicine to control $T_{2} D$ via metabolism monitoring and glucose predictions. Journal of Endocrinology and Diabetes. 2018;1(1):1-6.

2. Hsu GC. Using math-physical medicine to analyze metabolism and improve health conditions. video presented at the meeting of the $3 \mathrm{rd}$ international conference on endocrinology and metabolic syndrome 2018, Amsterdam, Netherlands. 2018.

3. Hsu GC. Using signal processing techniques to predict PPG for T2D. International Journal of Diabetes \& Metabolic Disorders. 2018;3(2):1-3.

4. Hsu GC. Using math-physical medicine and artificial intelligence technology to manage lifestyle and control metabolic conditions of T2D. International Journal of Diabetes \& Its Complications. 2018;2(3):1-7.

5. Hsu GC. A clinic case of using math-physical medicine to study the probability of having a heart attack or stroke based on combination of metabolic conditions, lifestyle and metabolism index. Journal of Clinical Review \& Case Reports. 2018;3(5):1-2. 